\section{COMMENT ON}

\section{doi $10.1308 / 003588409 \times 358953$}

AG Edwards, S Baynham, T Lees, DC Mitchell. Management of varicose veins: a survey of current practice by members of the Vascular Society of Great Britain and Ireland. Ann R Coll Surg Engl 2009; 91: 77-80

doi $10.1308 / 003588410 \times 12518836439443$

\section{Changing practice from conventional surgery to endovenous treatments produces excellent results for both long and short saphenous varicose veins}

\section{SHIVA DINDYAL, KENNETH R WOODBURN}

Department of Vascular Surgery, Royal Cornwall Hospital NHS Trust, Treliske, Truro, UK

\section{CORRESPONDENCE TO}

Shiva Dindyal, Department of Vascular Surgery, Royal Cornwall Hospital NHS Trust, Treliske, Truro, Cornwall TR1 3LJ, UK

E: doctordindyal@hotmail.com

This questionnaire study revealed a rationing of access to care of symptomatic varicose veins and that the majority of responders performed conventional surgery on the NHS. We agree with the findings of this study that endovenous treatments of superficial venous reflux are not yet widely available in NHS practice.

We have established an NHS day-case local anaesthetic endovenous service. Our initial experience with these techniques and their outcomes have consequently changed our venous practice overall.

All patients undergoing endovenous surgery (endovenous laser ablation [EVLA], radiofrequency ablation [VNUS closureFAST], or ultrasonography-guided foam sclerotherapy) by a single surgeon were entered into a venous database. Post-procedure clinical and venous duplex assessments were undertaken following treatment for all of our patients.

A total of 280 patients (334 limbs) underwent endovenous surgery and follow-up from April 2006 to June 2008. There were 227 women $(81.1 \%$ ) with a mean age of 57 years (range, 24-88 years). Of the study cohort, 144 had EVLA (110, long saphenous vein [LSV]; 34, short saphenous vein [SSV]), 153 had VNUS (123, LSV; 26, SSV; four perforators) and 37 had ultrasonography-guided foam sclerotherapy alone or in combination (26, LSV; 7, SSV; four perforators).

Clinical and duplex follow-up at a median of 24.3 weeks (range, 5-48 weeks) confirmed successful ablation in 96\% of LSV and $97.3 \%$ of SSV and $100 \%$ of perforators treated. Twelve of 334 (3.6\%) limbs required repeat treatment. Two patients had a presumed embolic phenomenon, a transient visual disturbance and a headache.
These preliminary results confirm the early success of endovenous treatment of the long saphenous system (96\% success) and indicate that these results can be replicated in the short saphenous system $(97.3 \%$ success $)$. These data support the view that endovenous treatment of varicose veins is superior to the reported results for conventional surgery in the short-term; long-term data are awaited.

Consequent on establishing an endovenous service, we have observed a large increase in the number of patients whose venous disease meets locally agreed criteria being referred for treatment. Preliminary costings, however, indicate that endovenous treatments generate a financial surplus when re-imbursed at tariff (Q11), as a result of reduced requirement for anaesthetic and theatre resources, with consequent cost benefits for our NHS trust. It remains to be seen whether or not this increased demand for a successful ambulatory treatment for a condition that is frequently perceived to be low priority by primary care trusts, will result in further restriction of access to these treatments for NHS patients.

\section{COMMENT ON}

\section{doi 10.1308/003588409X391884}

I Mitra, T Malik, J Homer, S Loughran. Audit of clinical coding of major head and neck operations. Ann R Coll Surg Engl 2009; 91 : 245-8

doi 10.1308/003588410X12518836439605

\section{Improving clinical coding accuracy}

ESMOND CARR, ASHA PILLAI

Department of ENT Surgery, West Middlesex Hospital, Middlesex, UK

CORRESPONDENCE TO

Esmond Carr, Department of ENT Surgery, West Middlesex Hospital, Twickenham Road, Isleworth, Middlesex TW7 6AF, UK

E: esmond@doctors.org.uk

This audit highlights three main areas of concern under the new Payment by Results system - the inaccurate coding, the overly complex coding system and the inappropriate HRG rating for some procedures. We were, however, disappointed that the authors did not have any intervention to suggest to improve things. We feel that it is the clinicians' responsibility to make sure that their activity is properly coded and the NHS trust's responsibility to make sure that changes happen to make sure that there is appropriate payment for procedures.

In a previously published audit, ${ }^{1}$ we increased the accuracy of coding from $69 \%$ to $95 \%$ in a single cycle. This was done by:

1. Agreeing between consultants and the coding department on how different procedures should be coded. 